\title{
Ageing Phenomena in a Cu-Al-Ni Alloy
}

\author{
N. Zárubová, A. Gemperle and V. Novák \\ Institute of Physics, Academy of Sciences of the Czech Republic, Na Slovance 2, 18040 Praha 8, \\ Czech Republic
}

\begin{abstract}
Effect of ageing on martensitic transformation has been investigated in a $\mathrm{Cu}-\mathrm{Al}-\mathrm{Ni}$ alloy. Single crystalline specimens were annealed for $30 \mathrm{~min}$ at temperatures $T_{a n}=175$ to $350^{\circ} \mathrm{C}$. Changes in the martensitic transformation were followed by calorimetry (DSC) and optical microscopy.Detailed observations of structural changes due to annealing were made by TEM. The most remarkable structural feature in the as-quenched $\beta_{1}$ phase are prismatic dislocation loops which have been formed by coalescence of excess quenched-in vacancies. Most probably, some off-stoichiometric Al atoms segregated to the plane of the loops during quenching. The first coherent precipitates of the equilibrium $\gamma_{2}$ phase are observed in the vicinity of the dislocation loops after ageing at $200^{\circ} \mathrm{C}$, and their size and density raise with increasing $\mathrm{T}_{\mathrm{an}}$. A linear increase of the transformation temperatures is observed for $\mathrm{T}_{\mathrm{an}}=200-300^{\circ} \mathrm{C}$. This shift can be most consequently explained by depletion of the matrix of Al atoms and annealing out of excess quenched-in vacancies. Moreover, stresses and concentration changes in the vicinity of the $\gamma_{2}$ precipitates could facilitate the nucleation of martensite. The DSC data as well as optical observations indicate that $\gamma_{1}$ ' martensite is induced in samples annealed at $T_{a n}$ up to $300^{\circ} \mathrm{C}_{j}$ whereas a different type of martensite suddenly appears in the samples aged above this temperature.
\end{abstract}

\section{INTRODUCTION}

It is well known that characteristics of shape memory alloys (SMA) can be considerably modified by ageing. A shift of the transformation temperatures, changes in the transformation hysteresis as well as improvement of the mechanical strength due to annealing have been well documented for a number of Cu-base SMA [1-8]. In some cases also a change of the transformation mode with ageing was observed, particularly a transition from the $\beta_{1} \leftrightarrow \beta_{1}^{\prime}$ transformation mode to the $\beta_{1} \rightarrow \gamma_{1}^{\prime}$ one was reported in $\mathrm{Cu}-\mathrm{Al}-\mathrm{Ni}[2,9,10]$. It is commonly accepted that changes in the type and degree of the short range atomic order of the quenched material take place during the initial stages of ageing, whereas precipitation of stable phases becomes dominant in the later stages, leading to decomposition of the metastable parent phase and in turn to the loss of the shape memory.

As for the CuAlNi system, three stages of ageing were described $[4,7]$. In the first stage, the transformation characteristics were found to remain generally stable, sometimes a slight decrease of the transformation temperatures was observed. In the second stage, the transformation temperatures increased without a remarkable change in the spread, hysteresis and enthalpy of the transformation. The third stage was described as a deterioration of the shape memory effect characterized by an increase in the transformation spread and hysteresis, and by a large decrease in the transformation enthalpy [4]. The increase of the transformation temperatures in stage 2 has not been unequivocally explained yet. Van Humbeeck et al.[7] ascribed it to the recovery of next-nearest-neighbour (nnn) order, and admitted also annealing out of excess vacancies. They claim not to have seen any precipitation during stage 2 . On the other hand, Rodriguez and Guénin [4 ] attributed the increase of the transformation temperatures during the second stage of ageing to the very beginning of precipitation of the phase $\gamma_{2}$ (intermetallic phase $\left.\mathrm{Cu}_{9} \mathrm{Al}_{4}\right)$.

In our recent study [11], calorimetry and transmission electron microscopy were utilized to follow the effect of ageing on martensitic transformation. Similarly to other investigators, three distinct stages of ageing were found in our isochronally annealed samples. We concentrated mainly on the first and second stage, with a special attention to the beginning of precipitation of the $\gamma_{2}$ phase, and discussed possible 
explanations of the observed increase of the transformation temperatures in stage 2 . The main results of the paper [11] will be summarised below, in Section 3. The aim of the present study was to extend our previous experiments and to investigate in more detail also the third stage where a sudden change of the transformation mode was observed.

\section{EXPERIMENTAL TECHNIQUES}

A single crystal ( $80 \mathrm{~mm}$ long, $22 \mathrm{~mm}$ in diameter ) of a nominal composition $\mathrm{Cu}-14.3 \mathrm{Al}-4.1 \mathrm{Ni}$ ( in wt\% ) was grown by the Bridgman technique. The as-grown crystal was annealed at $950^{\circ} \mathrm{C}$ for $1 \mathrm{~h}$ in an argon atmosphere and quenched into ice water. The resulting structure at room temperature was $\mathrm{DO}_{3}$ ordered $\beta_{1}$ austenite. Two rods with the longitudinal axes parallel to the growth axis were spark-cut from the central part of the quenched crystal. From these rods, samples in the form of platelets $6 \times 6 \times 0.3 \mathrm{~mm}^{3}$ were prepared by spark-cutting, mechanical grinding and polishing.

Ageing experiments were performed by annealing the samples in a Perkin-Elmer DSC 7 calorimeter for 30 min at temperatures $\mathrm{T}_{\mathrm{an}}=175$ to $350^{\circ} \mathrm{C}$ in a $\mathrm{N}_{2}$ atmosphere. The specimens were heated to and cooled from the temperature $\mathrm{T}_{\text {an }}$ with the maximum attainable rate of $200^{\circ} \mathrm{C} / \mathrm{min}, 2-4$ specimens were used for each annealing temperature. Calorimetry (DSC) and optical microscopy $(\mathrm{OM})$ were used to follow the martensitic transformations on the as-quenched and annealed samples. Transmission electron microscopy (TEM) was utilized to investigate the structural changes due to annealing.

The calorimetric measurements were carried out in the Perkin-Elmer DSC 7 differential scanning calorimeter in a $\mathrm{He}$ or $\mathrm{N}_{2}$ atmosphere, at cooling / heating rates of $10^{\circ} \mathrm{C} / \mathrm{min}$.

The optical observations were performed in an Opton microscope equipped with Nomarski interference contrast. The samples were cooled below the $\mathbf{M}_{\mathrm{f}}$ (martensite finish) temperature in an ethanol bath cooled by liquid nitrogen, and then slowly warmed above the $A_{f}$ (austenite finish) temperature. Both the forward and the reverse transformations were followed "in-situ" in the microscope.

The TEM observations were done on the as-quenched and annealed samples used before for DSC measurements and optical

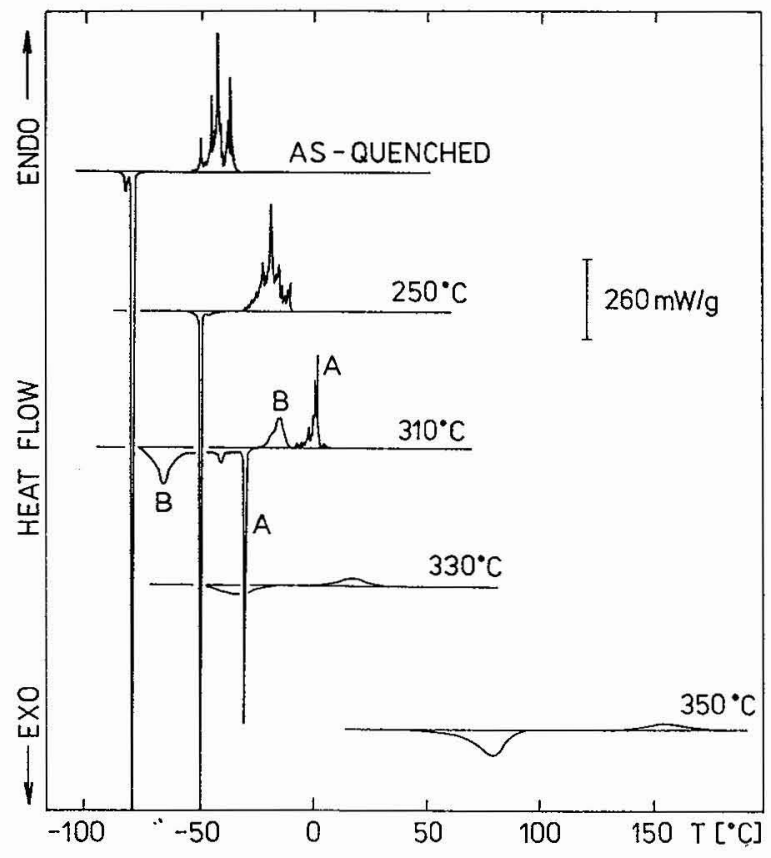

Fig. 1: DSC curves of samples annealed for $30 \mathrm{~min}$ at various temperatures. The curves relate to the sample mass of $1 \mathrm{~g}$. observations. Two discs $3 \mathrm{~mm}$ in diameter were punched out from each platelet after thinning it to $0.1 \mathrm{~mm}$. The foils were prepared by double-jet electropolishing in a $30 \%$ solution of $\mathrm{HNO}_{3}$ in methanol at $-15^{\circ} \mathrm{C}$, and examined in a Jeol $2000 \mathrm{FX}$ microscope operated at $200 \mathrm{kV}$.

\section{RESULTS AND DISCUSSION}

\subsection{Evolution of the DSC characteristics with ageing}

Representative thermograms ( heat flow vs. temperature ) of the as-quenched and aged samples are shown in Fig. 1. For the annealing temperatures $\mathrm{T}_{\text {an }}$ up to $\approx 300^{\circ} \mathrm{C}$, the forward transformations on cooling give rise to high and very narrow (less than $1^{\circ} \mathrm{C}$ ) exothermic peaks, whereas the reverse transformations on 
heating are accompanied by a set of relatively small sharp peaks stretching over $10-20^{\circ} \mathrm{C}$. The hysteresis width is about $40^{\circ} \mathrm{C}$ for the asquenched specimens, and decreases with ageing.

A pronounced change of the transformation characteristics takes place in the samples aged at $T_{\text {an }}=310^{\circ} \mathrm{C}$. For this annealing temperature, a second, rather broad and smooth peak appears on the DSC thermograms, indicating that the martensitic transformation proceeds in two steps, denoted hereafter as transformations $\mathrm{A}$ and $\mathrm{B}$. With increasing annealing temperature, the peak $A$ disappears and the peak $B$ is shifted to higher transformation temperatures. We should notice that the hysteresis width of the transformation $B$ is larger than that of the transformation $A$, and increases with raising temperature $\mathrm{T}_{\text {an }}$.

The peaks recorded during cooling and heating were integrated as a function of temperature. The temperatures corresponding to 0.1 and 0.9 transformed fractions were taken as the transformation start and transformation finish temperatures, respectively. The change of the transformation temperatures $M_{s}$ and $A_{f}$ with the annealing temperature $T_{\text {an }}$ is shown in Fig. 2. Ageing for $30 \mathrm{~min}$ at $\mathrm{T}_{\text {an }}$ up to $200^{\circ} \mathrm{C}$ does not invoke any distinct change in the transformation temperatures (stage 1). For higher $\mathrm{T}_{\text {an }}$ (stage 2), the transformation temperatures linearly increase, up to $\mathrm{T}_{\mathrm{an}}=300^{\circ} \mathrm{C}$. Closely above this annealing temperature the sudden change of the transformation mode takes place, as apparent from Fig. 2. The new transformation mode (B), operating in stage 3 , is characterized by an enormously steep dependence of the transformation temperatures on $T_{a n}$.

\subsection{Effect of ageing on the microstructure of the $\beta_{1}$ phase}

In this section, we shall briefly summarise results of our TEM observations made on the as-quenched and aged samples of the investigated alloy. These microstructural examinations were described in detail and documented by numerous micrographs in our recent paper [11]. The observations concern mainly precipitation of the equilibrium phase $\gamma_{2}\left(\mathrm{Cu}_{9} \mathrm{Al}_{4}\right)$. After annealing at temperatures $\mathrm{T}_{\text {an }}$ up to $300^{\circ} \mathrm{C}$, the $\mathrm{M}_{\mathrm{s}}$ temperature is still below zero (see Figs. 1,2 ) so that the structure of the TEM foils was the parent $\beta_{1}$ austenite. This allowed us to see some structural details which would probably not have been distinguishable in the martensite structure.

The most remarkable features of the as-quenched $\beta_{1}$ structure are large ( up to several $\mu \mathrm{m}$ ) prismatic dislocation loops with Burgers vectors in $\langle 100\rangle$ directions, and a fringe contrast attached to them (Fig. 3). The loops were undoubtedly formed by coalescence of excess vacancies into vacancy discs. The fringe contrast is most probably due to segregation of some off-stoichiometric $\mathrm{Al}$ atoms in the plane of the prismatic loop. The Al-enriched prismatic loops represent sites of preferential precipitation of the $\gamma_{2}$ phase during ageing. The first coherent precipitates were detected after ageing at $200^{\circ} \mathrm{C}$ (the end of stage 1): At the same time the fringe contrast disappears. A typical picture taken after anneal at $225^{\circ} \mathrm{C}$ is shown in Fig.4. At higher $\mathrm{T}_{\mathrm{an}}$ the precipitates coarsen and form long continuous rows in $\langle 100\rangle$ directions. In the samples aged for $30 \mathrm{~min}$ at $275^{\circ} \mathrm{C}$, the $\gamma_{2}$ precipitates are about $100 \mathrm{~nm}$ large and no more coherent.

With increasing volume fraction of the Al-rich $\gamma_{2}$ phase, the off-stoichiometric $\mathrm{Al}$ atoms must be eliminated from the matrix. In the samples aged at $300^{\circ} \mathrm{C}$, the volume fraction of $\gamma_{2}$ precipitates (mean size of about $200 \mathrm{~nm}$ ) was $\approx 0.04$. Under the assumption that the $\gamma_{2}$ phase is the stoichiometric $\mathrm{Cu}_{9} \mathrm{Al}_{4}$, the precipitates will bring about an overall depletion of the matrix by about 0.1 at. \% Al. During stage 3 


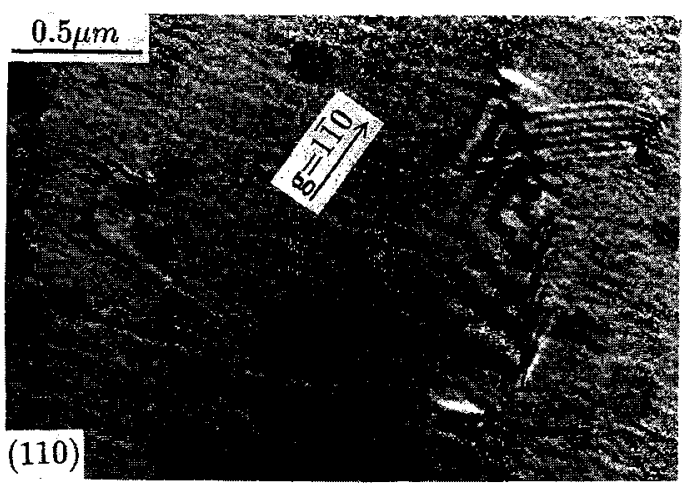

Fig. 3: TEM micrograph of the as-quenched structure. Dislocations in the $\beta_{1}$ matrix with fringe contrast.

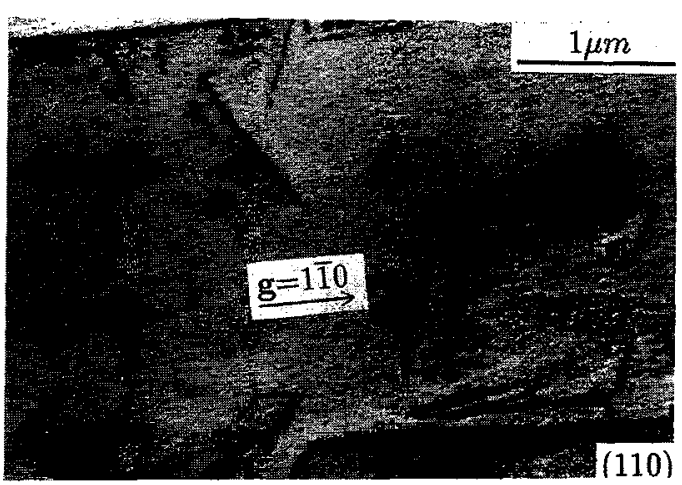

Fig. 4: Structure after anneal at $225^{\circ} \mathrm{C}$. Coherent precipitates in the vicinity of dislocation loops.

the volume fraction of the $\gamma_{2}$ phase rapidly increases, being $\approx 0.25$ in the samples annealed at $350^{\circ} \mathrm{C}$. Such amount of $\gamma_{2}$ precipitates could cause a depletion of the matrix by about 1 at. $\%(0.5 \mathrm{wt} . \%) \mathrm{Al}$.

In the as-quenched samples (and in the annealed samples too, as long as the structure of the foils remained austenite), the antiphase boundaries (APB's) having the antiphase vector $1 / 2 \mathrm{a}_{0}$ ' $\langle 100\rangle$ were well visible in 111 or 113 type superlattice reflections. On the other hand, the $1 / 4 a_{0}$ ' $\langle 111\rangle$ APB's were not found in 200 and 222 type superlattice reflections. The mean size of $1 / 2 \mathrm{a}_{0}^{\prime}\langle 100\rangle$ antiphase domains was about $0.1 \mu \mathrm{m}$ and, though carefully examined, no changes in the APB structure with annealing could be detected.

The samples annealed above $300^{\circ} \mathrm{C}$ either were in the martensite state at room temperature, or transformed to martensite during foil preparation and remained in this state henceforth (Fig. 6b). This allowed us to examine the martensite $B$ forming in stage 3 in detail. The results are presented in the next Section.

\subsection{Effect of ageing on the martensitic transformation}

\subsubsection{Change of the transformation mode}

"In-situ" optical observations of the as-quenched samples show large, very long martensite plates (such as those shown in Fig. 5a) going often through the whole specimen. The martensitic transformation is completed very rapidly, as corresponds to the narrow exothermic peak in Fig. 1. This transformation mode, denoted as mode A in Sec. 3.1, is obviously the $\beta_{1} \leftrightarrow \gamma_{1}^{\prime}$ (2H martesite) transition, as witnessed by the martensite morphology as well as by the hysteresis width (about $40^{\circ} \mathrm{C}$ in the as-quenched samples) and narrow exothermic peaks. Besides, the $2 \mathrm{H}$ martensite is generally reported to be thermally induced in $\mathrm{Cu}-\mathrm{Al}-\mathrm{Ni}$ alloys with compositions close to the initial composition of our alloy $[12,13]$.

The character of the martensite does not change noticeably due to ageing in stages 1 and 2 . The $\gamma_{2}$ precipitates, that are about $200 \mathrm{~nm}$ in size after annealing at $300^{\circ} \mathrm{C}$ and occupy approximately $4 \%$ of the sample volume, represent obviously no serious obstacles to the motion of the $\beta_{1} / \gamma_{1}$ ' interfaces.

The specimens aged for $30 \mathrm{~min}$. at temperatures around $310^{\circ} \mathrm{C}$ display two pronounced peaks (A,B, Fig. 1), both on cooling and heating. The "in-situ" optical observations show that the two transformation modes are well separated. On cooling, the typical $\gamma_{1}$ ' martensite needles (mode A) appear first in one part of the sample (Fig. 5a). The remaining part of the sample transforms later, on continued cooling. A typical example of martensite $B$ in a specimen aged at $310^{\circ} \mathrm{C}$ is shown in Fig. $5 \mathrm{~b}$. The needles are much smaller than those in Fig. 5a, yet still well visible in the optical microscope. With increasing annealing temperature the size of the needles of martensite $B$ rapidly decreases and the surface relief becomes very fine (Fig. 6a). A typical TEM micrograph of martensite B is shown in Fig. $6 \mathrm{~b}$. Fine twinning of the martensite plates can be well seen.

In order to identify the martensite B, many TEM diffractograms have been taken from individual martensitic plates under suitable tilting conditions. However, the evaluated interplanar distances agree 


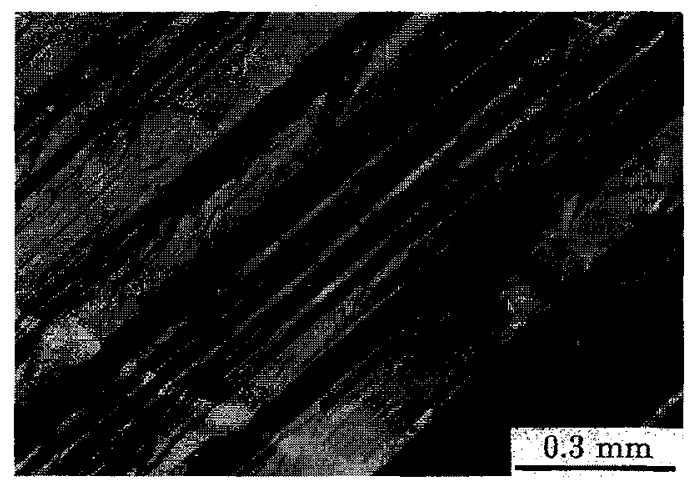

Fig. 5a: $2 \mathrm{H}$ martensite observed in one part of the sample annealed at $310^{\circ} \mathrm{C}$. (OM)

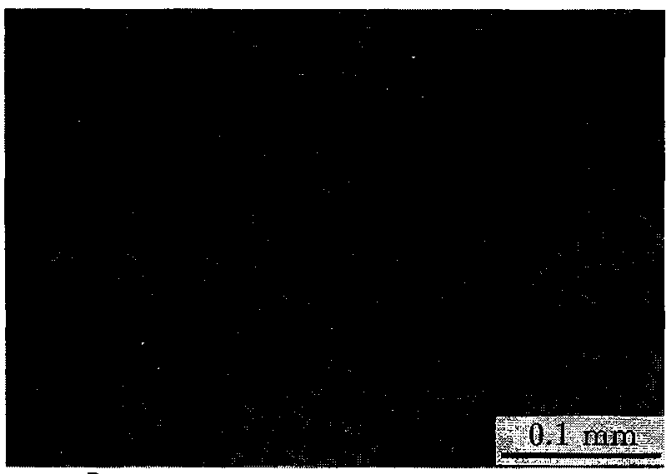

Fig. 6a: "Martensite $B^{\text {" }}$ as observed on the surface of the sample annealed at $330^{\circ} \mathrm{C}$. (OM)

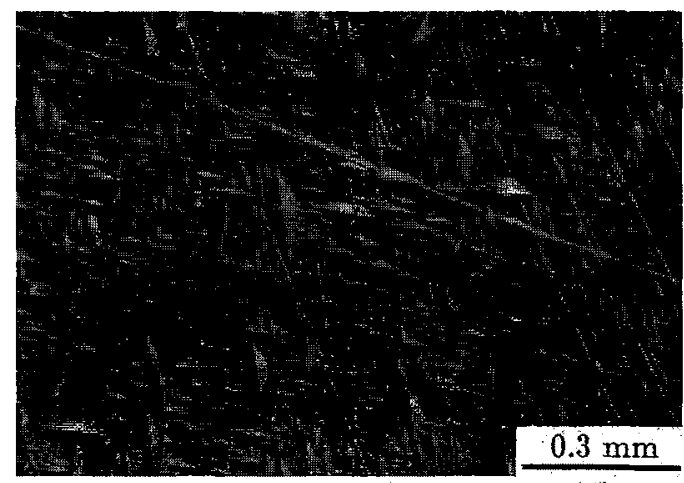

Fig. 5b: "Martensite $B^{\text {" }}$ observed in another part of the same sample annealed at $310^{\circ} \mathrm{C}$. (OM)

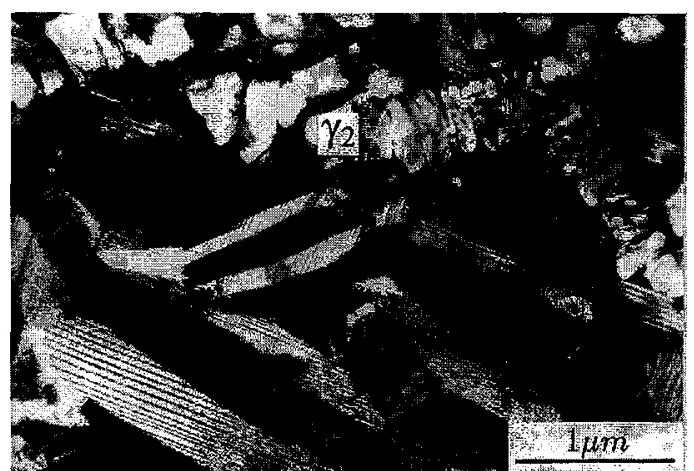

Fig. 6b: TEM micrograph of "martensite $B^{\text {" }}$ in the sample annealed at $330^{\circ} \mathrm{C}$.

satisfactorily with neither of the martensites found and described in Cu-Al-Ni alloys so far (see e.g.[14] for the lattice parameters), i.e. neither with $\gamma_{1}{ }^{\prime}(2 H)$, nor with $\beta_{1}^{\prime}(18 R)$, nor with $\alpha_{1}^{\prime}(6 R)$ strutures. This fact is rather surprising. We would expect a change from $\beta_{1} \leftrightarrow \gamma_{1}^{\prime}$ to $\beta_{1} \leftrightarrow \beta_{1}^{\prime}$ on annealing since the estimated depletion of the matrix by $\approx 1$ at. $\% \mathrm{Al}$ in stage 3 due to $\gamma_{2}$ precipitation shifts the alloy to the composition where such change could occur [13].

Anyway, we have observed a change from the $\beta_{1} \leftrightarrow \gamma_{1}$ ' to a $\beta_{1} \leftrightarrow$ "martensite $B$ " transition. As far as we know, similar observations performed on CuAINi alloys with compositios close to our alloy [2,9] indicated a change from the $\beta_{1} \leftrightarrow \beta_{1}^{\prime}$ transition to the $\beta_{1} \leftrightarrow \gamma_{1}^{\prime}$ one. Also Morawiec and Gigla [10] who investigated an alloy with $13.4 \mathrm{wt} \% \mathrm{Al}$ reported the change from the $\beta_{1}$ ' martensite to $\gamma_{1}$ ' on ageing. It just illustrates the complexity of the ageing phenomena.

\subsubsection{Shift of the transformation temperatures}

It is obvious from our DSC measurements and optical observations that the character of the $\beta_{1} \rightarrow \gamma_{1}$, transformation was not appreciably affected by ageing at temperatures $T_{\text {an }}$ up to $300^{\circ} \mathrm{C}$, though a pronounced shift of the transformation temperatures in the stage 2 is apparent from Fig. 2 . Various explanations of this shift of $T_{t}$ have been proposed in the literature, however, as discussed in detail in [11], the explanations cannot be easily applied to our experiments.

The idea that the shift of $M_{S}$ and $A_{f}$ in stage 2 is due to an improvement in the second neighbour order [7] contradicts with the fact that in our alloy precipitation of the $\gamma_{2}$ phase takes place during stage 2 
(first $\gamma_{2}$ precipitates have already been found after ageing at $200^{\circ} \mathrm{C}$ ). Whereas the improvement of the nnn order requires only a short-range reordering of the $\mathrm{Al}$ atoms, long-range diffusion must be involved in the precipitation of $\gamma_{2}$. The coincidence of the two processes is improbable.

The elastic stresses and concentration changes in the vicinity of the $\gamma_{2}$ precipitates [4] could perhaps facilitate the nucleation of the $\gamma_{1}^{\prime}$ martensite, and consequently shift $M_{s}$ to higher temperatures. This mechanism fails, however, as soon as the $A_{s}$ and $A_{f}$ temperatures are considered. At $T_{a n}=225^{\circ} \mathrm{C}$ the precipitates are still very small and their density is very low (see Fig. 4). Although the close vicinity of the precipitates might represent "soft" places for martensite formation and, consequently, "hard" places for the reverse $\gamma_{1}$ ' $\rightarrow \beta_{1}$ transformation, far from the precipitates the matrix should remain unaffected. In that case we expect that the $\beta_{1}$ austenite will nucleate at those unaffected places without any increase in $A_{s}$. Nevertheless, a marked increase of $A_{s}$ and $A_{f}$ was observed already in samples aged at $225^{\circ} \mathrm{C}$.

An explanation of the observed shift of the transformation temperatures during ageing might be annealing out of the excess quenched-in vacancies as suggested in [7]. We have estimated [11] that about $10^{-4}$ of the quenched-in vacancies must have condensed into the vacancy discs forming the observed prismatic dislocation loops (see Sec.3.2). However, vacancy concentrations as high as $10^{-2}$ have been reported for the $\mathrm{DO}_{3}$ ordered structures after quenching $[15,16]$. This idea is further supported by the resistometric measurements performed on aged samples of the investigated alloy [17] which show a continuous decrease of the resistivity through the whole stage 2 . Annealing out of the excess vacancies, together with the elimination of the off-stoichiometric $\mathrm{Al}$ atoms from the matrix due to $\gamma_{2}$ precipitation, will increase the $\mathrm{DO}_{3}$ order. Consequently, the equilibrium temperature $\mathrm{T}_{0}$, and in turn the transformation temperatures could increase.

An explanation of the sudden change from the martensite $\gamma_{1}$ ' to the "marensite $B^{\text {" }}$ and the extremely steep increase of the transformation temperatures of the "martensite $B$ " in stage 3 remain unclear at

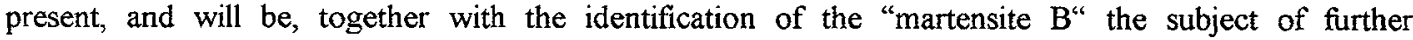
investigations.

\section{Acknowledgement}

A financial support of the Grant Agency of the Academy of Sciences of the Czech Republic under Contract No. A1010621 is highly appreciated.

\section{References}

[1] Kennon N.F., Dunne D.P.and Middleton L., Metall. Trans. A 13 (1982) 551-555.

[2] Sakamoto H.and Shimizu K., ISIJ International 29 (1989) 395-404.

[3] Tadaki T. and Shimizu K., Shape Memory Materials, MRS Int. Mtg.on Adv. Mats.,Vol. 9, Materials Research Society, 1989, pp. 291-404.

[4] Rodríguez. P. and Guénin G., Mater. Sci. Eng.A 129 (1990) 273-277.

[5] Matsushita K., Okamoto T. and Okamoro T., J. Mater. Sci. 20 (1985) 689-699.

[6] Dutkiewicz J., Cesari E., Seguí C. and Pons J., J. de Physique IV, Colloq. C4, Vol.1 (1991) 229-234.

[7] Van Humbeeck J., Chandrasekaran M. and Delaey L., ISIJ International 29 (1989) 388-394.

[8] Morawiec H. and Gigia M., Acta Metall.Mater. 42 (1994) 2683-2686.

[9] Van Humbeeck J., Van Hulle D., Delaey L., Ortín J., Seguí C. and Torra V., Trans. JIM 28 (1987) 383-391.

[10] Morawiec H. and Gigla M., J. de Physique IV, Colloq. C8, Vol.5 (1995) 937-942.

[11] Zárubová N., Gemperle A. and Novák V., Mater. Sci. Eng.A 222 (1997) 166-174.

[12] Otsuka K., Wayman C.M., Nakai K., Sakamoto H. and Shimizu K., Acta Metall. 24 (1976) 207-226.

[13] Friend C.M., Maňosa Ll., Ortín J. and Planes A., J. de Physique IV, Colloq. C4, Vol.1 (1991) 71-76.

[14] Otsuka K., Ohba T., Tokonami M. and Wayman C.M., Scripta Metall.Mater. 29 (1993) 1359-1364.

[15] Shaefer H.-E., Würschum R. and Bub J., Materials Science Forum Vols. 105-110 (1992) 439-450.

[16] Yamaguchi M. and Shirai Y., Physical Metallurgy and processing of Intermetallic Compounds (Chapman and Hall, New York) pp.3-27.

[17] Daříček T., Novák V., Bartuška P. and Lašek J., submitted to Scripta Materialia. 